\section{POTASSIUM AND PARALYSIS}

BY

\section{P. E. JACKSON, M.D., M.R.C.P.}

AND

\section{M. OAKLEY, M.B., B.S. Royal Free Hospital}

This paper presents a further case of the uncommon but striking syndrome of hypokalaemic periodic paralysis associated with potassium-losing nephritis. A similar case, together with a review of previously published cases known or considered to be examples of this syndrome, has recently been reported (Evans and Milne, 1954).

\section{Case Report}

The patient, a housewife, was first admitted to hospital in November, 1948, when she was 34 years old, with a threemonths' history of giddiness. She was found to be moderately hypertensive (B.P. 210/130). There was no past history of renal disease. Albuminuria was present, and a few hyaline casts were seen in the centrifuged deposit of the urine. Urea clearance was $103 \%$.

The patient kept quite well until she was seen again in the out-patient department on August 3,1953. She then gave a two-weeks history of pain behind the right eye. Her blood pressure was unchanged. She had partial third and fourth cranial nerve palsies on the right. She was admitted to hospital, and on September 3 she lost consciousness following an exacerbation of her headache and was found to have had a subarachnoid haemorrhage. On September 18, after a right carotid arteriogram, which showed a small aneurysm at the origin of the posterior communicating artery, the right common carotid artery was ligated.

She was seen from time to time as an out-patient, and in June, 1954, complained of some intermittent weakness and cramps in her arms and legs. On questioning, she admitted to similar symptoms occasionally for about six years. She also had slight premenstrual swelling of the ankles. Physical examination revealed no fresh abnormality.

TABLE I

\begin{tabular}{|c|c|c|c|c|c|c|}
\hline & $\begin{array}{c}\text { Nov. }{ }^{10} \\
1948\end{array}$ & $\begin{array}{c}\text { Nov. } 16 \\
1954\end{array}$ & $\operatorname{Nov.25}_{1954^{*}}$ & $\begin{array}{l}\text { Dec. } 1 \\
1954 \dagger\end{array}$ & $\begin{array}{l}\text { Dec. } 2 \\
1954 \ddagger\end{array}$ & $\begin{array}{c}\text { Feb. } 10 \\
1955\end{array}$ \\
\hline 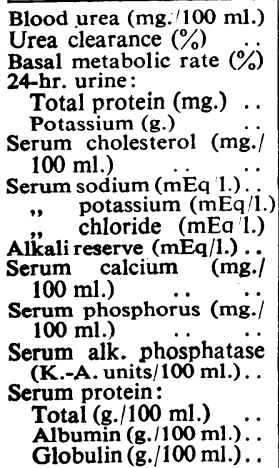 & $\begin{array}{r}20 \\
103\end{array}$ & $\begin{array}{c}34 \\
58 \\
+3 \\
540 \\
2 \cdot 2 \\
156 \\
142 \\
2 \cdot 6 \\
94 \\
32\end{array}$ & $\begin{array}{c}144 \\
2.5 \\
97 \\
31 \\
12.2 \\
2.7 \\
8.5 \\
8.4 \\
5.6 \\
2.8\end{array}$ & $\begin{array}{c}149 \\
4 \cdot 6 \\
109 \\
31 \\
10 \\
3 \cdot 1\end{array}$ & $\begin{array}{c}142 \\
3 \cdot 1 \\
102 \\
29\end{array}$ & $\begin{array}{c}2.2 \\
33 \\
10 \cdot 6\end{array}$ \\
\hline
\end{tabular}

* Day before balance. †Third day of potassium supplement. ‡Day after potassium discontinued.

TABLE II.-Urinary Acidification Test. (5 g. $(94 \mathrm{mEq})$ Ammonium Chloride Given at 9.45 a.m.)

\begin{tabular}{l|c|c|c|c}
\hline Time: & 9.45 a.m. & 11.45 a.m. & 1.45 p.m. & 3.45 p.m. \\
\hline $\begin{array}{l}\text { pH of urine (a) } 0 \% \\
\text { Ammonia (mEq/hour) }\end{array}$ & $\begin{array}{l}6.9 \\
0.61\end{array}$ & $\begin{array}{l}7.2 \\
2.1\end{array}$ & $\begin{array}{l}6.9 \\
0.9\end{array}$ & $\begin{array}{c}7.0 \\
1.2\end{array}$ \\
\hline
\end{tabular}

In October she said that her "fingers had dropped" in an attack of weakness. The attack lasted a few hours. She was asked to attend immediately she had another attack, and was seen next on November 3. She then had paralysis of the extensors of the fingers of the left hand and weakness of plantar flexion of the right foot, with absence of the corresponding tendon reflexes. This attack lasted about 24 hours. There were no sensory changes. Direct electrical stimulation of the extensors of the fingers of the left hand failed to produce any response. Electromyograms showed no spontaneous activity, and a reduced.number of small and polyphasic motor unit potentials on volition. A diagnosis of periodic paralysis was made. Trousseau's sign was positive when there was periodic paralysis (Fourman and McCance, 1955) or when there was marked muscle weakness. Although the patient complained of cramps at these times there was no spontaneous tetany.

There was no family history of any similar attacks. Attacks could not be provoked by large carbohydrate meals, insulin (up to 16 units soluble insulin only, because of the danger of a more profound hypokalaemia), cold, or exercise, although the patient said that the attacks tended to follow unwonted exertion on previous days.

Further investigations revealed a persistently lowered serum potassium at about $2.5 \mathrm{mEq}$ (normal 3.9-5.2 $\mathrm{mEq})$. Serum cholesterol, sodium, chlorides, calcium, phosphorus, alkaline phosphatase, urea, and alkali reserve were consistently normal. Plasma proteins were normal. Urea clearance showed an average value of $58 \%$. There was $0.5 \mathrm{~g}$. of protein per 24-hour urine (Table I). Maximum urine concentration was to S.G. 1016 only. Ingestion of $5 \mathrm{~g}$. of ammonium chloride caused no increase in the acidity of the urine during the following six hours, although there was a moderate increase of ammonia production (Table II). The intravenous pyelogram was normal. The plasma hydrocortisone was within normal limits at $5.5 \mu \mathrm{g}$. per $100 \mathrm{ml}$. No aldosterone could be detected in the plasma. The salivary sodium/potassium ratio was also normal at 0.42 A sodium and potas-

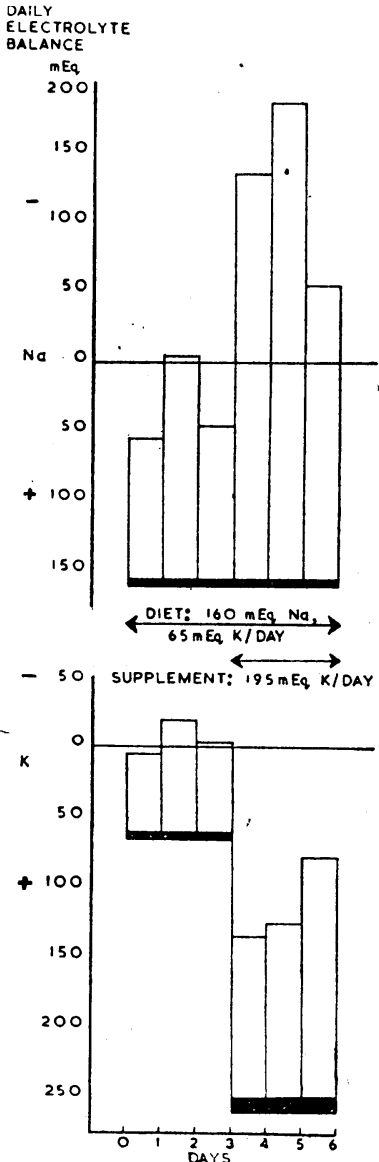

Chart showing the sodium and potassium ba!ance. sium balance was carried out with a diet containing 65 $\mathrm{mEq}$ of potassium and $160 \mathrm{mEq}$ of sodium daily (see Chart).

During the first three days there was no gross evidence of lack of equilibrium of sodium or potassium. Then 195 $\mathrm{mEq}$ of potassium was added as $3 \mathrm{~g}$. of potassium chloride five times daily. There was immediate excretion of sodium and marked retention of potassium, suggesting replacement of an intracellular potassium deficit which had been partly compensated for by a raised intracellular sodium. The serum potassium rose to $4.6 \mathrm{mEq} / \mathrm{litre}$. The serum potassium fell immediately the supplement was stopped.

During the time of the potassium supplement the patient said that she felt fitter than she had done for many months, and lost all her residual muscle stiffness. 
Electrocardiograms showed changes consistent with hypokalaemia (Schwartz et al., 1954 ; McAllen, 1955) during the attacks of paralysis. These changes were not evident during the period of potassium supplement.

Comment.-This case illustrates the classical features of the periodic paralysis syndrome-namely, intermittent paralysis associated with absence of the tendon reflexes in the affected muscles. The absence of reaction to direct electrical stimulation of the affected muscles confirmed the diagnosis. The persistent hypokalaemia and the response to potassium therapy indicated-that this was in fact a case of hypokalaemic paralysis. The disturbed kidney function shown by the common tests of renal function, the negative potassium balance, and the otherwise normal blood chemistry indicate potassium-losing nephritis. It seems likely that the renal changes were secondary to benign hypertension and not to pyelonephritis as in similar reported cases. Primary aldosteronism was excluded by the absence of detectable aldosterone in the plasma.

\section{Discussion}

The syndrome of periodic paralysis has been reported in association with hypokalaemia and in other conditions with no apparent disorder of potassium metabolism. The classical example is family periodic paralysis (Talbott, 1941). In this condition hypokalaemia is typically present only during the paralytic attacks. Since there is no loss of potassium from the body, it is assumed that there is movement of potassium into cells (Danowski et al., 1948). Swelling of the affected muscles has been noted during attacks. Histologically, swelling of muscle fibres with vacuolation is seen (Bickerstaff, 1953). Hypokalaemic periodic paralysis has also been noted in the recovery phase of diabetic coma (Nabarro et al., 1952), thyrotoxicosis (Weissman, 1952), porphyrinuria (Thompson and Parrish, 1953), the Fanconi group of syndromes (Milne et al., 1952 ; Bickel et al., 1953), potassium-losing nephritis (Evans and Milne, 1954), the diuretic phase of acute tubular necrosis (Bull et al., 1949), uretero-colic anastomosis (Diefenbach et al., 1951), sprue and Addison's disease over-treated with deoxycortone acetate (Black, 1953), liquorice and para-aminosalicylate administration (Cayley, 1950; Strong, 1951), and now in primary aldosteronism (Conn, 1955).

Clinically, there is an acute onset of flaccid paralysis which commonly affects, primarily or solely, the extensor muscles of the limbs. The bulbar and respiratory muscles are usually spared, and there is no sensory loss. The electromyogram (E.M.G.) shows that the muscle is inexcitable either directly or through its motor nerve (Adams et al., 1953a).

Periodic Paralysis with Uncertain or No Known Relation to Ponassium Metabolism.-Otherwise typical family periodic paralysis has been reported in which no abnormality of potassium metabolism could be demonstrated (Tyler et al., 1951 ; J. Pediat., 1953). Periodic paralysis has also been reported in association with adiposo-genital dystrophy (Prader and Zellweger, 1952), dystrophia myotonica (Bredemann, 1952), and after meningitis (Kjerulf-Jensen et al., 1951). In the post-meningitic case and the patient with adiposo-genital dystrophy there was a persistent hypokalaemia. It is possible that these attacks may be due to disturbances of hypothalamic electrolyte-regulating centres.

Hyperkalaemic Paralysis. - Widespread paralysis has been noted in the terminal stages of uraemia, with hyperkalaemia (Merrill et al., 1950; Bull et al., 1953). Similar paralysis has been induced in the over-treatment of hypokalaemia by intravenous potassium salts (Finch et al., 1946). It is possible that hyperkalaemia may also contribute to the paralysis in paroxysmal myohaemoglobinuria (Buchanan and Steiner, 1951) and the crush syndrome (Oliver et al., 1951). Clinically, there is usually a symmetrical ascending flaccid paralysis. It is frequently fatal from acute respiratory failure. Increased myotatic irritability and increased tendon reflexes have : been noted:: also paraesthesiae and objective sensory loss. These findings are all in contrast to those in hypokalaemic paralysis.
Relation of Potassium to Paralysis.--In hypokalaemia there is no constant relation between the serum level and the site or extent of the paralysis or even its occurrence. In hyperkalaemia there is a much closer correlation.

In family periodic paralysis it is generally assumed that the defect is at the muscle membrane (Adams et al., 1953b). However, we have been unable to find any reports of nerveconduction studies in family periodic paralysis or in other hypokalaemic syndromes. It is possible that there may also be a conduction defect in the peripheral nerve or even at a higher level, although the distribution does not usually suggest a nerve lesion.

The possibility of peripheral nerve or central nervous system dysfunction seems more likely in hyperkalaemic paralysis, where sensory changes have frequently been reported.

\section{Summary}

A case of potassium-losing nephritis with periodic paralysis is described.

Hypokalaemic and hyperkalaemic paralysis and related conditions are discussed.

The relation of these conditions to potassium metabolism is considered.

We wish to thank Dr. Thompson Hancock for permission to publish. We also thank him and Drs. Helen E. Dimsdale, A. T. Richardson, and D. N. Baron for much help and useful criticism; also Dro O. Garrod for the aldosterone estimation.

REFERENCES

Adams, R. D., Denny Brown, D., and Pearson, C. M. (1953a). Disease of Muscle, p. 519. Cassell, London.

Bickel, H., Smallwood, W. C., Smellie, J. M., and Hickmans, E. M. (1953). Acta paediat. (Uppsala), 42, Suppl. 90, p. 27.

Bickerstaff, E. R. (1953). J. Neurol. Neurosurg. Psychiat., 16, 178.

Black, D. A. K. (1953). Lancet, 1, 357.

Bredemann, W. (1952). Airztl. W schr., 7, 202.

Buchanan, D.. and Steiner, P. E. (1951). Arch. Neurol. Psychiat. (Chicago),

Bull, 66, 107. M., Carter, A. B., and Lowe, K. G. (1953). Lancet, 2, 60.

Joekes, A. M., and Lowe, K. G. (1949). Ibid., 2, 229.

Cayley, F. E. de W. (1950). Ibid., 1. 447.

Conn, J. W. (1955). J. Lab. clin. Med., 45, 6.

Danowski, T. S., Elkinton, J. R., Burrows, B. A., and Winkler, A. W. (1948). J. clin. Invest., 27, 65.

Diefenbach, W. C. L., Fisk, S. C., and Gilson, S. B. (1951). New Engl. J. Med., 244, 326.

Evans, B. M. and Milne, M. D. (1954). British Medical Journal, 2, 1067. Finch, C. A., Sawyer, C. G., and Flynn, J. M. (1946). Amer. J. Med., 1, 337.

Fourman, P., and McCance, R. A. (1955). Lancet, 1, 329

J. Pediat., 1953, 42, 751 .

Kjerulf-Jensen, K., Krarup, N. B., and Warming-Larsen, A. (1951). Lancet, 1. 372.

McAlien, P. M. (1955). Brit. Heart J., 17. 5

Merrill, J. P., Levine, H. D., Somerville, W., and Smith, S. (1950). Ann. intern. Med., 33, 797 .

Milne, M. D., Stanbury, S. W., and Thomson, A. E. (1952). Quart. J. Med., 21, 61.

Nabarro, J. D. N., Spencer, A. G., and Stowers, J. M. (1952). Lancet. 1, 986

Oliver, J., MacDowell, M., and Tracy, A. (1951). J. clin. Invest., 30, 1305. Prader, A., and Zellweger, H. (1952). Helv. paediat. Acta, 7, 42

Schwartz, W. B., Levine, H. D., and Relman, A. S. (1954). Amer. J. Med., 16, 395 .

Strong, J. A. (1951). Brittsh Medical Journal, 2, 998.

Talbott, J. H. (1941). Medicine (Baltimore), 20, 85.

Thompson, C. W., and Parrish. A. E. (1953). Med. Ann. Distr. Columbia,

22, 177

Tyler, F. H.,. Stephens, F. E., Gunn, F. D., and Perkoff, G. T. (1951).

Weissman, L. (1952). J. clin. Endocr., 12, 1223.

The Israeli Ministry of Health has marked the occasion of the Third World Congress of the Israeli Medical Association by publishing a pamphlet entitled Israel Health Services. This traces the growth of these services from the department set up by the British Civil Mandatory Administration. Voluntary health organizations substantially helped the Ministry, and in 1954 W.H.O. aid totalled 34,800 dollars. At first the unrestricted flow of unselected immigrants caused an acute shortage of medical staff. By June, 1955, however, there was one doctor per 440 of population. Much has been accomplished during the first seven years: the incidence of typhoid, diphtheria, typhus fever, tuberculosis, and venereal disease has fallen considerably. Acute poliomyelitis is now the chief problem. Most of the cases are in children under 5 years of age. 